\title{
INOVAÇÃO E MUDANÇAS DE PARADIGMAS ATRAVÉS DA GESTÃO 4.0 NA BUSCA DO DIFERENCIAL COMPETITIVO NAS ORGANIZAÇÕES
}

\author{
https://dx.doi.org/10.48097/2674-8673.2021n5p12
}

Ana Paula Barbosa de Oliveira ${ }^{1}$
Djailton Paz Dias da Silva ${ }^{2}$
Susimary Leitão

RESUMO

O objetivo deste trabalho é destacar a inovação e as mudanças de paradigmas através da gestão 4.0 na busca do diferencial competitivo nas organizações, investigando os elementos intervenientes da tomada de decisão. Para isso é necessário compreender as peculiaridades da inovação tecnológica, analisando as abordagens relevantes sobre a gestão eficiente, evidenciando as mudanças tecnológicas sob os aspectos da cultura organizacional. A metodologia apresentada neste trabalho foi elaborada com base em pesquisa bibliográfica, explorativa, qualitativa, visando fundamentar teoricamente os conceitos com base em autores renomados. Ficou constatado que os gestores possuem responsabilidades dentro das organizações a fim de empregar uma abordagem de mudança no gerenciamento de processos que ajude a organização a se adaptar às mudanças introduzidas pela implementação de soluções e inovações tecnológicas.

Palavras-chave: Inovação. Mudanças. Gestão 4.0. Diferencial Competitivo.

Data de submissão: 26/03/2021

Data de aprovação: 05/05/2021

\begin{abstract}
The objective of this work is to highlight innovation and paradigm changes through 4.0 management in the search for competitive advantage in organizations, investigating the intervening elements of decision making. For this, it is necessary to understand the peculiarities of technological innovation, analyzing the relevant approaches on the management of efficient changes, highlighting technological changes under aspects of organizational culture. The methodology presented in this work was developed based on bibliographic, exploratory, qualitative research, aiming to theoretically base the concepts based on renowned authors. It was found that managers have responsibilities within organizations in order to employ an approach to change in process management that helps the organization to adapt to the changes introduced by the implementation of technological solutions and innovations.
\end{abstract}

Keywords: Innovation. Changes. Management 4.0. Competitive Differential.

\footnotetext{
${ }^{1}$ Concluinte do Curso de Gestão em Recursos Humanos da Faculdade Metropolitana da Grande Recife.

E-mail: anapaulabarbosa19993@gmail.com

${ }^{2}$ Concluinte do Curso de Gestão em Recursos Humanos da Faculdade Metropolitana da Grande Recife.

E-mail: djjaisilva@gmail.com

${ }^{3}$ Professora Orientadora do Curso de Gestão em Recursos Humanos da FMGR.

E-mail: susimary@gmail.com
} 


\section{INTRODUÇÃO}

A primeira revolução industrial consistiu na mecanização dos processos de produção por meio de dispositivos e máquinas de água e vapor em um campo tecnológico, o que resultou em uma mudança drástica em todos os aspectos da vida humana. Nessa ordem de ideias, a segunda revolução industrial marcou novas formas de produção em massa e de organização das empresas, além de começar a usar a eletricidade como energia.

A terceira revolução industrial se destaca pelo uso de computadores para automatizar esses processos de produção, mas apenas em termos de força bruta. Os computadores controlavam automaticamente as máquinas que realizavam o trabalho físico que exigia força bruta. Não havia inteligência real aplicada e nenhuma análise. Basicamente, o trabalho físico estava mudando para máquinas automatizadas.

Essa quarta revolução difere das anteriores, pois as tecnologias, além de obviamente mais avançadas, caracterizam-se por serem de natureza inteligente em termos de coleta e análise de dados, aprendizado de máquina, comunicação em rede, entre outros aspectos tecnológicos. Isso implica avanços importantes na computação e em outras áreas científicas que permitem que os computadores se tornem cada vez mais automáticos e inteligentes.

A justificativa deste trabalho está pautada na gestão 4.0, nas decisões descentralizadas, que são definidas como a capacidade dos sistemas de tomar decisões inteligentes por conta própria, com base em informações. Um exemplo disso é um sistema embarcado inteligente que, ao receber dados de sensores, decide, através de um mecanismo previamente programado, se deve acelerar ou reduzir a produção, alcançando assim um diferencial competitivo no mercado no qual atua.

O objetivo geral deste trabalho é destacar a inovação e mudanças de paradigmas através da gestão 4.0 na busca do diferencial competitivo nas organizações. Já os objetivos específicos são estudar o diferencial competitivo, investigar os elementos intervenientes da tomada de decisão na gestão 4.0, compreender as peculiaridades da inovação tecnológica, analisar as abordagens relevantes sobre a gestão de mudanças eficientes, evidenciar as mudanças tecnológicas sob os aspectos da cultura organizacional e, por fim, abordar os desafios e perspectivas na gestão das indústrias 4.0 frente às mudanças tecnológicas. 


\section{UM OLHAR SOBRE O DIFERENCIAL COMPETITIVO}

De acordo com Rumelt (2011), o mercado concorrencial, nos dias de hoje, tem impulsionado as organizações a buscarem vantagens competitivas para se destacarem de seus concorrentes. Como consequência, o conceito de vantagem competitiva aparece consideravelmente nas discussões que envolvem estratégias de negócios empresariais.

Existe dificuldade para a definição de um conceito que defina na sua totalidade a expressão vantagem competitiva, no entanto, parece ser muito utilizada a associação deste com o tema da criação de valor. (RUMELT, 2011).

Porter (1980 apud Magretta, 2018) discorre que as vantagens competitivas são o elo fundamental da performance de uma empresa em mercados dinâmicos e competitivos. Assim, as vantagens competitivas geram custos baixos de vantagens diferenciais, ou de uma estratégia bem sucedida focada no sucesso organizacional.

De acordo com o Rumelt (2011), diferentes organizações de consultoria em estratégias fazem a análise de vantagem competitiva em termos de retornos obtidos aos acionistas. No entanto, a estratégia competitiva tem oferecido um número muito reduzido de técnicas analíticas para a obtenção de sua compreensão, sendo que economistas estudam há muito tempo as estruturas empresariais com grandes perspectivas da política pública aliada aos interesses das organizações.

Braga (2010) destaca que:

Os agentes do mercado incluíam compradores, fornecedores e produtores. Os
ganhos totais negociáveis estariam maximamente disponíveis pela atribuição entre
os agentes. Eles concluíram que o valor máximo apropriado é limitado pelo valor
agregado de cada agente para o jogo, com o valor total do jogo sendo incrementado
pela presença dos agentes. Para a obtenção de um valor agregado positivo, um
participante deve ser diferente de seus competidores, sendo detentor de uma
assimetria positiva. (BRAGA, 2010, p. 13).

Já de acordo com Barney (2011), a estratégia de uma empresa é definida como a sua teoria de como obter vantagem competitiva, embora seja difícil predizer a maneira exata como a competição em um setor evoluirá e, portanto, raramente é possível saber com certeza se uma empresa está escolhendo a estratégia certa, por isso, a estratégia de uma empresa é quase sempre uma teoria, ou seja, é a sua melhor aposta sobre como a competição vai se desenvolver e como essa evolução pode ser explorada para que conquiste a vantagem competitiva. 
Figura 1 - Modelo de pedras angulares de vantagem competitiva

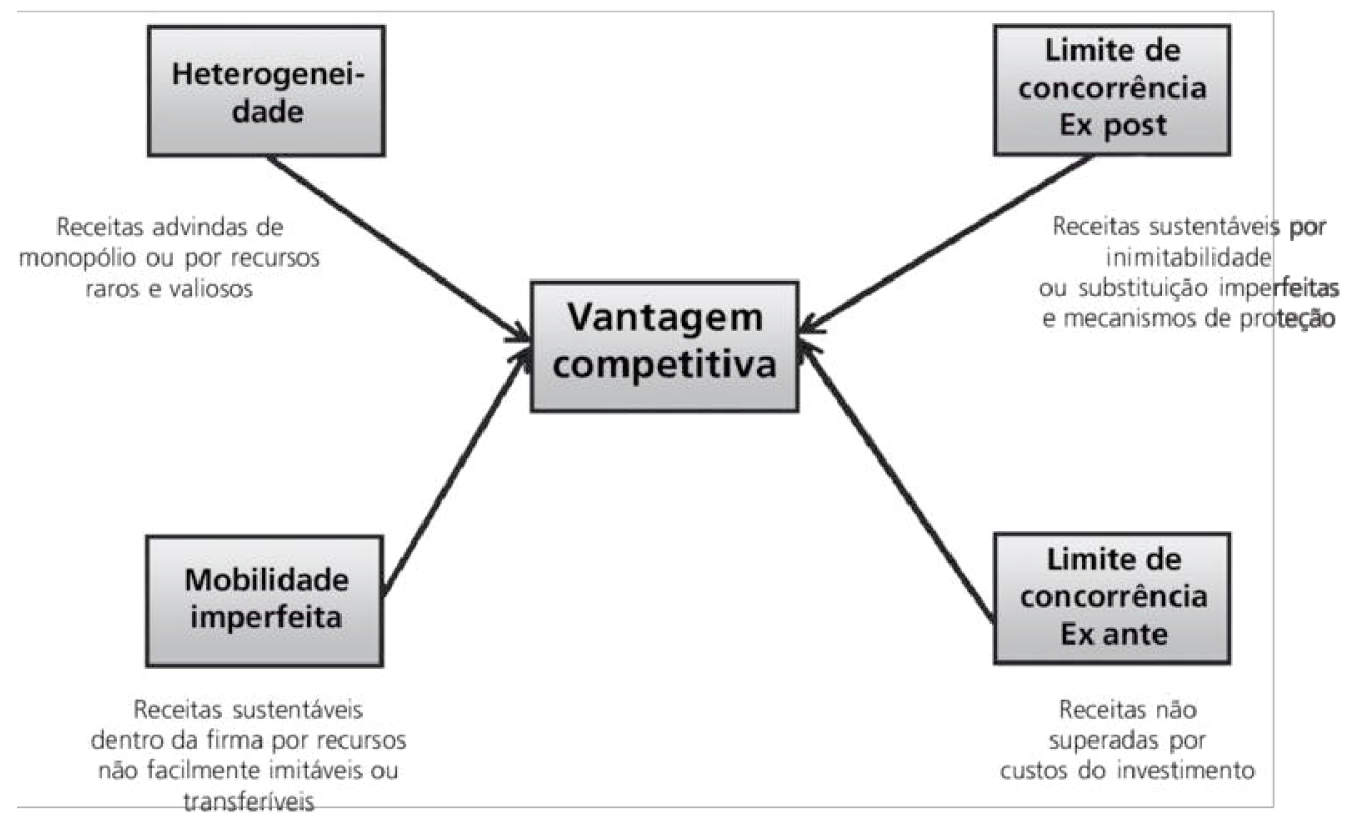

Fonte: adaptado de Braga (2010)

Embora seja difícil saber com certeza se uma empresa está seguindo a melhor estratégia, é possível reduzir a probabilidade de erros. Diante disso, a melhor maneira é escolher a estratégia da empresa de forma cuidadosa e sistemática, além de acompanhar o processo de administração estratégica, constituída por um conjunto sequencial de análises e escolhas que podem aumentar a probabilidade de uma empresa escolher uma boa estratégia, isto é, uma estratégia que gere vantagens competitivas. (BARNEY, 2011).

Conforme pensamento de Porter (1980 apud Magretta 2018), o desempenho de qualquer empresa pode ser dividido em duas partes: a primeira, originada do desempenho médio de todos os concorrentes; e a segunda, originada do desempenho relativo da empresa do setor. $\mathrm{O}$ alinhamento de todas as atividades de uma organização em torno de uma estratégia competitiva torna mais fácil a sua implementação e comunicação com clientes, empregados e acionistas. Um posicionamento estratégico que não seja claro, sem explicação, dificulta a construção dos recursos necessários, criando problemas de coordenação interna. Dessa forma, a posição mais crítica em termos de posicionamento estratégico seria a região central.

De acordo com Magretta (2018), a rivalidade competitiva é um processo implacável que combate a capacidade da empresa de identificar e manter uma vantagem, porém existem conceitos errôneos sobre competição e, como esta funciona, dão origem a erros em estratégia, 
dentre eles, o mais comum é de que o sucesso competitivo resulta de ser o melhor, sendo essa mentalidade altamente intuitiva e também autodestrutiva.

Segundo Porter (1980 apud Crainer, 2015), a abordagem sobre estratégia vinculou-se do sucesso ao posicionamento, dividindo o ambiente competitivo em cinco forças, sendo elas: 'rivalidade entre concorrentes', 'poder de negociação dos fornecedores', 'poder de negociação dos clientes', 'ameaça de produtos entrantes' e 'ameaça de produtos substitutos', as quais as empresas devem estar atentas, fazendo algumas considerações sobre como as empresas podem utilizar sua avaliação para adotar uma que assegure maior vantagem estratégica.

A estratégia de vantagem competitiva está ligada ao modo como a empresa organiza suas atividades, pois se utiliza de uma abordagem baseada em sistemas para dissecar a análise das atividades de uma empresa e o modo como ela usa suas atividades para criar valor. Como coloca Porter, o valor é criado quando uma empresa utiliza recursos à sua disposição para transformar insumos em produtos ou serviços que os consumidores possam adquirir. (PORTER, 1980 apud CRAINER, 2015).

\section{Elementos intervenientes da tomada de decisão na gestão 4.0}

A tomada de decisão, independentemente da estratégia adotada, implica na avaliação de alternativas que envolvem riscos. A tomada de decisão arriscada está carregada de incertezas que existem quando as pessoas não sabem o que acontecerá. (WEITEN, 2008). Com o propósito de reduzir incertezas e melhorar as decisões, os indivíduos deveriam basear suas decisões em processos racionais, estabelecendo a resposta mais coerente para determinada solução do problema. (BAZERMAN, 2004).

No século passado era comum encontrarmos líderes que centralizavam o poder de decisão neles mesmos, pois não acreditavam na capacidade de seus subordinados. Poucos eram os líderes que, diante da necessidade de delegar tarefas, descobriam que seus subordinados possuíam habilidades de tomar decisões. Hoje, os líderes se esforçam em motivar os seus subordinados, capacitando-os com informação, treinamento, confiando a eles tarefas complexas, pois as informações chegam em nosso meio de forma muito mais rápida. Diante disso, nas organizações do novo século, o homem é parte de uma rede de pensadores e comunicadores, sendo a tarefa principal do líder motivar e manter essa rede funcionando. Portanto, as informações que eram desprezadas no passado, hoje devem ser mostradas a todos os colaboradores da organização no qual todos representam um fator de crescimento para a organização. (BAZERMAN, 2004). 
Os métodos de administração e de gestão sofrem mudanças ao longo dos anos, entretanto, prevalece o trabalho individualizado, resultando em uma competição entre as pessoas, porém quando o trabalho tem o foco em equipe, a gestão se torna participativa. O processo de tomada de decisão é necessário para identificar as questões envolvidas e descobrir alternativas com o uso da criatividade e da capacidade analítica, avaliando assim as ações a serem tomadas e descobrir alternativas disponíveis através da gestão participativa ao alterar conceitos como trocar o chefe pelo líder. Ao mudar a postura e a maneira de atuar, todos os empregados deixam de ser meros executores e passam a gerir seu trabalho e contribuir na gestão da empresa, adotando assim a forma de trabalho através de equipes, atuando de forma coesa, integrada e participativa. (BAZERMAN, 2004).

As decisões dentro da organização que possui uma gestão 4.0 podem ser classificadas quanto à atividade administrativa a que ela pertence seguindo três níveis:

- Nível operacional: utilização eficaz e eficiente das instalações existentes e todos os recursos para executar as operações. A decisão de nível operacional é um processo pelo qual se assegura que as atividades operacionais sejam bem desenvolvidas.

- Nível tático: engloba a aquisição genérica de recursos e as táticas para a localização de projetos e novos produtos. As decisões, no nível tático, são normalmente relacionadas com o controle administrativo.

- Nível estratégico: envolve a definição de objetivos, políticas e critérios gerais para planejar o curso da organização. O propósito das decisões, no nível estratégico, é desenvolver estratégias para que a organização seja capaz de atingir seus macro objetivos. (ANTHONY, 1965, p. 180).

De acordo com Bazerman (2004), o modelo racional de tomada de decisão está fundamentado em elementos que definem a forma pela qual a decisão deve ser tomada, e não como ela realmente é. O modelo de tomada de decisão, segundo o autor, é apresentado nas seguintes fases:

1) Definição do problema;

2) Identificação dos critérios relevantes para a tomada de decisão;

3) Ponderação dos critérios, atribuindo preferências;

4) Conhecimento de todas as alternativas relevantes;

5) Avaliação das alternativas de a cordo com os critérios identificados para cada decisão;

6) Identificação da melhor solução.

Muito embora decidir seja uma ação em si no sentido lato, diferencia-se da implementação por ser um caminho de ação já escolhido, mas que ainda precisa ser concretizado no decorrer do tempo. Portando, decidir diferencia-se da implementação no 
sentido preciso do exame laboral, havendo lapsos de tempo maiores ou menores conforme a posição da hierarquia das decisões. (ABRAHAN, 2011).

Nas decisões estratégicas há mais distinção e implementação enquanto na decisão operacional a ação e a decisão praticamente se confundem. Em contrapartida, uma separação ou integração mais precisa entre decisão e ação dependerá de exame mais analítico do contexto que envolve a decisão do líder. (ABRAHAN, 2011).

Segundo Robbins (2014):

O fato é que, diferentemente do que acontece na maioria das indústrias hoje, em uma gestão 4.0 todos os dados da empresa estarão disponíveis para acesso em tempo real. A partir desse ponto, deve-se preocupar com a extração de informações úteis desses dados para que, efetivamente, se alcance a precisão nas tomadas de decisão esperada para a Indústria 4.0 Os dados coletados pelos sistemas tecnológicos da Indústria 4.0 são de grande importância para a tomada de decisões, mas não geram informações de valor por si só. É necessário que estes sejam encaminhados a profissionais capazes de analisá-los e interpretá-los, transformando dados crus em decisões fundamentadas e que tragam benefícios e diferencial competitivo para a empresa. (ROBBINS, 2014, p. 41).

Kazmier (1975 apud Abrahan 2011) afirma de forma pragmática que a habilidade em tomar decisões é a chave do planejamento bem sucedido em todos os níveis de gestão, sendo que isso envolve mais que uma seleção de planos de ação, havendo assim pelo menos três fases: diagnóstico, descobertas de alternativas, e análises.

\section{As peculiaridades da inovação tecnológica}

Desde os anos 1950 o Brasil vem estruturando sua rede de base para ciência, tecnologia e inovação. Diante disso, surgiram inúmeras organizações e, consequentemente, leis e políticas públicas para alavancar a inovação, prioritariamente nas pequenas e médias empresas brasileiras. Entretanto, a cultura, o cenário burocrático brasileiro, o financiamento público e privado limitado, a falta de infraestrutura para o desenvolvimento das ideias, o desconhecimento da aplicação das leis e políticas de incentivos, impedem que a inovação seja deslanchada para níveis adequados ao desenvolvimento pretendido no país. (TERRA, 2019).

Além dos itens descritos como atividades de inovação, os custos e os riscos foram apontados, de acordo com o IBGE (2018), como uma das principais dificuldades para se inovar no Brasil, pois estão relacionados com gastos dispendidos pelas empresas em relação ao PIB, uma vez que como os custos e riscos são elevados há uma tendência de que os gastos nesse processo de inovação sejam menores.

As empresas dependem dos ambientes internos e externos para a sua manutenção e desenvolvimento. Terra (2019) frisa que a interação entre universidades, governo e empresas 
é altamente relevante para a inovação acontecer, principalmente de cunho tecnológico, conseguindo estabelecer paradigmas organizacionais, entre elas as incubadoras de empresas.

No Brasil existem dois principais incentivos ficais à inovação nas empresas: incentivos fiscais P\&D em qualquer setor industrial, previstos na LB, no capitulo III, regulamentada pelo decreto 5.798/2006, acrescida da lei 11. 487/2007, regulamentada pelo decreto 6.260/2007; e Lei 11.774/2008, porém o correto entendimento e interpretação dos artigos e parágrafos inclusos nas respectivas leis podem ser um diferencial para utilizar ou não um incentivo fiscal, nos quais os contabilistas podem ajudar a diminuir as diferenças e dificuldades entre os empresários inovadores por não se tratar de uma tarefa simples. (TERRA, 2019).

\section{Abordagens relevantes sobre a gestão de mudanças eficientes}

De acordo com Johann (2018), em um mundo globalizado, no qual as organizações estão diante do recorrente desafio de se adequar aos novos tempos, elas se caracterizam por sucessivas mudanças que se processam no macroambiente. Efetuar adequações na cultura e na estratégia da empresa é algo que merece atenção da alta administração da organização. As mudanças que se processam no macroambiente geram instabilidade, mas também comportam oportunidades para novos negócios, produtos e serviços.

A sobrevivência de todo e qualquer tipo de empresa não mais depende do porte de cada organização, mas decorre, ao longo dos anos, de sua capacidade de se adaptar aos novos tempos. Portanto, deve-se ter em mente que a gestão da mudança não implica necessariamente em uma drástica mudança cultural, mas sim em um processo de gradual ajustamento e de suporte da cultura da empresa ao projeto de mudança organizacional palnejada. (JOHANN, 2018).

Quando a empresa se dispõe a demandar o gerenciamento da sua cultura, sintonizando-a com os processos de mudanças planejadas, há condições de criar e de manter atitude coletiva energizada, entusiástica e assertiva no quadro funcional da empresa. (JOHANN, 2018). 
Figura 2 - Evolução da gestão da mudança organizacional

\begin{tabular}{|c|c|}
\hline Definiçăo encontrada & Referência \\
\hline $\begin{array}{l}\text { Conjunto de teorias, valores, estratégias e técnicas cientificamente embasadas, } \\
\text { visando mudança planejada do ambiente de trabalho com o objetivo de elevar o } \\
\text { desenvolvimento individual e o desempenho organizacional. }\end{array}$ & $\begin{array}{l}\text { Porras e } \\
\text { Robertson } \\
(1992)\end{array}$ \\
\hline $\begin{array}{l}\text { Acontecimento temporal estritamente relacionado a uma logica, ou ponto de vista } \\
\text { individual, que possibilita às pessoas pensarem e falarem sobre a mudança que } \\
\text { percebem. }\end{array}$ & $\begin{array}{l}\text { Ford e Ford } \\
\text { (1995) }\end{array}$ \\
\hline $\begin{array}{l}\text { Resposta da organização às transformaçōes que vigoram no ambiente, com o intuito } \\
\text { de manter a congruência entre os componentes organizacionais (trabalho, pessoas, } \\
\text { arranjos/estrutura e cultura). }\end{array}$ & $\begin{array}{l}\text { Nadler et al. } \\
\text { (1994) }\end{array}$ \\
\hline $\begin{array}{l}\text { Qualquer transformaçăo de natureza estrutural, estratégica, cultural, tecnológica, } \\
\text { humana ou de outro componente, capaz de gerar impacto em partes ou no } \\
\text { conjunto da organizaçăo. }\end{array}$ & Wood Jf. (2000) \\
\hline $\begin{array}{l}\text { Qualquer modificação, planejada ou nåo, nos componentes organizacionais formais } \\
\text { e informais mais relevantes (pessoas, estruturas, produtos, processos e cultura); } \\
\text { modificaçăo que seja significativa, atinja a maioria dos membros da organizaçăo } \\
\text { e tenha por objetivo a melhoria do desempenho organizacional em resposta às } \\
\text { demandas intemas e externas. }\end{array}$ & Bressan (2001) \\
\hline
\end{tabular}

Fonte: adapatado de Bourne (2014)

A gestão de mudanças envolve, de acordo Bourne (2014), quatro elementos no processo de tranformação:

1) Analisar a necessidade de mudança e decidir como deveria ser, com base em analises;

2) Planejar e administrar a mudança como um projeto ou uma série de projetos;

3) Implementar a mudança e gerenciar as pessoas por meio dela;

4) Assegurar que a mudança se torne bem enraizada de modo que não seja arruinada.

Administrar a mudança, em termos gerais, resume-se em persuadir as pessoas a trabalhar de maneira diferente, seja com um equipamento novo, de uma nova estrutura ou com um diferente conjunto de processos, agindo de forma concreta sobre como fazer e agir, a fim de evitar imprevistos. Certamente, quanto mais claro for o retrato do objetivo a ser alcançado, mais capaz de conquistar o compromisso de outros em relação às metas organizacionais. (BOURNE, 2014).

Segundo Bourne (2014), se a organização não muda em resposta ao ambiente em que opera, irá fracassar. Do mesmo modo as pessoas têm que mudar e se adaptar conforme as circunstancias. Gerenciar a mudança é uma tarefa difícil e dolorosa, podendo ser até emocionalmente desgastante, envolvendo uma gama de habilidades desde o planejamento de 
projetos, passando a influenciar aqueles que provavelmente serão afetados, até assegurar que as ações apropriadas aconteçam.

\section{As mudanças tecnológicas sob os aspectos da cultura organizacional}

A única forma efetiva de mudar a organização é através de sua cultura, pois a sua sedimentação está ligada ao processo do conhecimento e relacionada por intermédio da construção de significados. Na realidade, não se tem uma única cultura nas organizações, pois o correto a se dizer nos dias atuais se coloca como as culturas presentes em uma organização, evidenciando, assim, a preocupação na relação com os outros, focando na necessidade de entender contextos e questões que se alteram a cada discurso incorporado pelas pessoas nas organizações. (GARCIA, 2015).

O tema cultura organizacional tem ganhado relevância nos últimos anos, tanto pelo crescimento no número de pesquisas, quanto pelo enfoque teórico metodológico. Os controles baseados em cultura sob a perspectiva de relação com os controles gerenciais formais constituem o ambiente no qual os demais controles se inserem. Trata-se de um fenômeno complexo e que compreende diferentes fatores, de modo que se tem desenvolvido modelos em que se agrupam várias características da cultura em duas dimensões, resultando em diversos tipos culturais. (MENEGON, 2012).

A cultura organizacional molda os comportamentos sociais, como destaca Garcia (2015), exercendo o papel de incentivadora ou inibidora de práticas e formas de conduta, de modo que tem sido estudada com sua relação com o desempenho e como parte do sistema de controle gerencial.

Ainda de acordo com Garcia (2015), a cultura organizacional não pode ser abordada explicitamente porque é considerada antes como um fator contingente, uma variável de contexto, um elemento de controle em que esse autor propõe um modelo de análise de sistemas de gerenciamento de desempenho.

As organizações devem se preocupar com o monitoramento das informações e a abertura do diálogo com seus diferentes grupos de interesses, entendendo que o seu comportamento deve ir muito além do repasse de informações, tendo consistência da sua cultura, para que todos tenham acesso. (MENEGON, 2012).

Como destaca Silva (2015):

A relação entre tecnologia, inovação e produção do conhecimento, bem como suas dimensões no contexto organizacional vêm evoluindo ao longo do tempo, desta forma, vale-se da história para resgatar questões que nesta perspectiva permanecem contemporâneas, impactando na estrutura de gestão das empresas modernas. Entende-se que a compreensão desse processo por parte das empresas/organizações 
contribuirá para a busca de modelos, métodos ou práticas inovadoras que levem em conta a importância da produção do conhecimento para a geração de inovação. No decorrer do último século as mudanças no mundo do trabalho têm ocorrido de forma vertiginosa, alterando estruturas, hierarquia, tecnologias e as exigências sobre os trabalhadores, levando os dirigentes a efetuarem constantes mudanças em suas organizações com o objetivo de mantê-las estáveis, eficientes e em desenvolvimento. (SILVA, 2015, p. 32).

A cultura organizacional pode ser fortemente caracterizada por ter grande influência do modo de como as pessoas pensam e se comportam e que, consequentemente, todos acreditam e atendem às metas e práticas da empresa, principalmente na área de inovação e tecnologia. É uma verdadeira vantagem para a organização se os comportamentos que encorajam e facilitam forem apropriados. O ponto fraco de uma cultura organizacional que encoraja comportamentos errados é dificultar gravemente os esforços da empresa para operar as mudanças adequadas. (MENEGON, 2012).

\section{Os desafios e perspectivas na gestão das indústrias 4.0 frente às mudanças tecnológicas}

A indústria e suas várias revoluções, sem dúvida, mudaram completamente a maneira como a humanidade trabalha. A primeira revolução industrial ocorreu em 1760, no final do século XVIII. Essa grande mudança ocorreu na Grã-Bretanha e depois se espalhou para o resto da Europa. A economia começou a depender da produção local, embora, no início, não estivesse acostumada ao mercado internacional. Essa nova forma de economia mudou o cenário social e a estrutura de classes. (SANTOS, 2018).

A segunda revolução industrial ocorreu em 1870. Sem dúvida, com o surgimento da energia elétrica, todo o cenário mundial é completamente mudado. Organizações capitalistas foram estabelecidas com força, a mídia sofreu mudanças abismais, assim como o transporte. Os produtos de eletricidade e petróleo começaram a substituir rapidamente a energia do vapor. (SANTOS, 2018).

A terceira revolução foi apenas alguns anos atrás, no final do século 20, com o surgimento da eletrônica e do mundo da internet. Essa foi uma mudança radical na maneira como as pessoas se comunicavam e entendiam a sociedade. Com essa mudança, o que foi mais revolucionado foram os meios de comunicação que continuam cada vez mais aperfeiçoados. (SANTOS, 2018).

Está a caminho uma quarta revolução industrial. Por vários anos a ideia de robótica foi refinada e é possível que a próxima grande mudança que a indústria tenha sobre a humanidade esteja intimamente ligada a essa questão. Diante disso, a indústria remove os fundamentos da 
humanidade toda vez que se reinventa. É isso que estamos vendo com a manufatura aditiva, uma nova mudança de paradigma na produção. (SANTOS, 2018).

Segundo Sacomano (2018), com a indústria 4.0 nos referimos ao movimento tecnológico caracterizado por uma rede de conexão de computadores na qual ocorre uma troca permanente e instantânea de informações, além do estreito vínculo entre computadores do mundo real e do mundo virtual. Nesse sentido, esses avanços tecnológicos são enquadrados nos contextos comercial e industrial, de modo a melhorar a qualidade dos processos industriais e melhorar a produtividade dessas organizações, com base no desenvolvimento e aumento do poder de computação dos dispositivos.

O desenvolvimento de sensores e comunicações sem fio, bem como o desenvolvimento do potencial computacional, permitem o desenvolvimento e a experimentação de tecnologias emergentes, como a realidade virtual e a realidade aumentada. No caso da visão artificial, é uma tecnologia que usa câmeras para capturar imagens e vídeos cujos dados capturados são usados pelos computadores para processá-los. (SACOMANO, 2018).

Para Almeida (2019), no setor industrial, apesar de os sistemas de realidade aumentada ainda estarem em estágios muito iniciais de seu desenvolvimento tecnológico, eles são capazes de fornecer serviços no nível industrial, como a seleção de peças do armazém, reparo e manutenção, treinamento e montagem das máquinas.

O novo paradigma tecnológico estabelecido e que está começando a se desenvolver na indústria 4.0 terá um impacto progressivo em todos os aspectos da vida humana. O desenvolvimento de tecnologias vinculadas a sensores, poder computacional e o desenvolvimento de algoritmos de reconhecimento de imagem são uma oportunidade para empresas de todo o mundo promoverem e facilitarem o crescimento e o acesso a essas tecnologias para melhorar a produtividade, não apenas em um quadro de referência industrial, mas também para o consumo do público além do entretenimento. (ALMEIDA, 2019).

\section{METODOLOGIA}

Trata-se de um estudo realizado através da pesquisa bibliográfica de caráter exploratório e descritivo. Para a realização da mesma foi efetuado um levantamento de publicações científicas relacionadas com a temática da pesquisa. O critério de inclusão dos artigos foi ser trabalho de pesquisa publicado em periódicos nacionais em língua portuguesa.

Foram consultadas as bases de dados informatizadas: o portal SCIELO (Scientific Eletronic Library Online) e livros. Durante a coleta e análise foram encontrados artigos e 
livros com publicações que atendiam aos objetivos propostos, sendo excluídos os que na leitura do resumo não apresentavam relação com o tema da pesquisa.

Para síntese e análise do material foram realizados os seguintes procedimentos: leitura exploratória, que constitui na leitura do material para saber do que se tratavam os artigos; leitura seletiva, que se preocupou com a descrição e seleção do material quanto a sua relevância para o estudo; leitura crítica e reflexiva, que buscou por meio dos dados a construção dos resultados encontrados.

Este estudo tem como base a pesquisa exploratória, pois a "investigação exploratória é realizada em área na qual há pouco conhecimento acumulado e sistematizado". (MASCARENHAS, 2013).

Desenvolvida com base em material já elaborado como livros, artigos e teses, a pesquisa bibliográfica possui caráter exploratório, pois permite maior familiaridade com o problema, aprimoramento de ideias ou descoberta de intuições. No caso específico de pesquisas avançadas onde se exige certo ineditismo e originalidade na contribuição, a revisão bibliográfica desempenha um papel preponderante. (GIL, 2007).

\section{RESULTADOS}

A apresentação e a análise dos dados servirão, como primeiro passo, para saber em que estado se encontra atualmente o problema, que trabalhos já foram realizados a respeito, e quais são as opiniões reinantes sobre o assunto. Como segundo passo, permitirá que se estabeleça um modelo teórico inicial de referência, da mesma forma que auxiliará na determinação das variáveis e na elaboração do plano geral da pesquisa. (MASCARENHAS, 2013).

A globalização atual está causando à economia mundial um profundo processo de mudança. As empresas têm buscado aplicar estratégias para minimizar os impactos ambientais negativos de seus produtos e processos, ao mesmo tempo em que intensific am sua competitividade. Um dos diferenciais das empresas é o lançamento antecipado dos produtos e a capacidade de desenvolvê-los com os objetivos de atender às crescentes necessidades e expectativas dos clientes.

O evento que desencadeia a mudança pode ser a adoção de uma nova estratégia, tecnologia, organização ou habilidade, ou na melhor das hipóteses, esse evento pode ser uma oportunidade para a organização alcançar o sucesso, tendo assim como principal foco no desempenho humano, ou seja, ajuda a organização a capturar o benefício de uma 
oportunidade, influenciando o desempenho humano para se obter uma gestão de mudança eficaz.

Na gestão 4.0 as mudanças podem ser aplicadas através de muitas ideias diferentes dos campos de negócios, como desenvolvimento organizacional e psicologia, uma vez que as mudanças nas organizações se tornam mais frequentes para a sobrevivência, incluindo a liderança de mudanças tecnológicas. Também evoluiu pra abranger mais habilidades e conhecimentos no qual a avaliação de desempenho serve para mensurar os mesmos, facilitando a sua administração.

Figura 3 - Principais impactos e mudanças após a adoção de uma gestão 4.0

\begin{tabular}{l|l}
\multicolumn{1}{c|}{ En 2015 } & \multicolumn{1}{c}{ En $\mathbf{2 0 2 0}$} \\
\hline 1- Solução de problemas complexos & \multicolumn{1}{c}{ 1- Solução de problemas complexos } \\
2- Relacionamento com os outros & 2- Pensamento crítico \\
3- Gestão de pessoas & 3- Criatividade \\
4- Pensamento crítico & 4- Gestão de pessoas \\
5- Negociação & 5- Empatia com os outros \\
6- Controle de qualidade & 6- Inteligência Emocional \\
7- Orientação para serviços & 7- Bom senso e tomada de decisões \\
8- Bom senso e tomada de decisões & 8- Orientação para serviços \\
9- Escuta ativa & 9- Negociação \\
10- Criatividade & 10- Flexibilidade Cognitiva \\
\end{tabular}

Fonte: Adaptado de Johann (2018)

Constatando que na gestão 4.0 as mudanças não podem ser um trabalho somente para uma pessoa ou uma única equipe, os papéis necessários para realizar o plano de gestão de mudanças incluem executivos, líderes, especialistas de RH, colaboradores e recursos designados em uma equipe de projetos em que a avaliação do sucesso das mudanças se mede através do grau dos objetivos da transformação alcançados.

\section{CONSIDERAÇÕES FINAIS}

Ficou constastado no decorrer desse trabalho, ao atingir seus objetivos, que os gestores possuem responsabilidades dentro da organização a fim de empregar uma abordagem de mudança no gerenciamento de processos que ajude a organização a se adaptar às mudanças introduzidas pela implementação de soluções e inovações tecnológicas. As organizações cada vez mais sofrem intensivo impacto das tecnologias, pois a automação avança rapidamente tanto nos escritórios como nos processos industriais, atingindo, incluisive, as indústrias mais tradicionais.

Diante disso, observa-se que toda a economia moderna dependerá cada vez mais da ciência e da tecnologia, no qual assumem uma posição estratégica com profundas implicações 
nas tomadas de decisões, pois nas próximas décadas não haverá nação verdadeirmaente soberana que não disponha de um eficiente sistema de ino vação tecnologica na vanguarda das organizações.

A tranformação digital é a nova corrida do ouro em busca de vantagem competitiva para garantir a sustentabilidade das organizações ao redor do mundo. Por questão de sobrevivência, no ambiente dos negócios, as empresas estão acelerando o passo para realizarem mudanças, até mesmo em sua cultura organizacional, em prol das inovações. Porém, ainda existem diversas lacunas e incertezas quanto ao futuro. A boa utilização da tecnologia é a questão central na busca pelo aumento de produtividade nas organizações, auxiliando a levar informação para os decisores na forma e no tempo adequado, obtendo assim um diferencial competitivo, mesmo nos tempos de mudanças originadas pelos avanços tecnologicos.

\section{REFERÊNCIAS}

ABRAHAN, S. O. Y. Tomada de decisão nas organizações. São Paulo: Editora Saraiva, 2011.

ALMEIDA, P. S. Industria 4.0: princípios básicos, aplicabilidade e implantação na área industrial. São Paulo: Editora Saraiva, 2019.

ANTHONY, R. N. Planning and Control Systems. Cambridge: Havard University Press, 1965.

CRAINER, S. Estratégia: arte e ciência na criação e execução. Porto Alegre: Bookman, 2015.

BARNEY, J. B. Administração estratégica e vantagem competitiva. São Paulo: Editora Pearson, 2011.

BOURNE, M. Gestão de mudanças em uma semana. São Paulo: Figurati, 2014.

BRAGA, A. Strategic Sourcing: a transformação estratégica das empresas compradoras - parte 1. Artigos Instituto ILOS: Rio de Janeiro, 2010.

BAZERMAN, M. Processo decisório. Rio de Janeiro: Campus, 2004.

GARCIA, A. B. Influência da cultura organizacional na gestão participativa nas organizações. Rio de Janeiro: Revista de Pesquisa Cuidado é Fundamental. v. 7, n. 2. AbrilJunho, 2015.

GIL, A. C. Métodos e técnicas de pesquisa. São Paulo: Editora Atlas, 2007. 
JOHANN, S. L. Gestão de mudança e cultura organizacional. Rio de Janeiro: FGV, 2018.

MASCARENHAS, S. Metodologia Científica. São Paulo: Pearson Educational do Brasil, 2013.

MAGRETTA, J. Entendendo Michael Porter. Rio de Janeiro: Alta Books, 2018.

MENEGON, L. F. Comportamento organizacional. São Paulo: Editora Pearson, 2012.

ROBBINS, S. P. Fundamentos do comportamento organizacional. São Paulo: Pearson Educational do Brasil, 2014.

RUMELT, R. P Estratégia boa, estratégia ruim: descubra suas diferenças e importância. São Paulo: Elsevier, 2011.

SACOMANO, J. S. Industria 4.0. São Paulo: Blucher, 2018.

SANTOS, S. Introdução à indústria 4.0. São Paulo: Editora Atlas, 2018.

SILVA, N. Percepções dos gestores sobre os comportamentos dos funcionários em situações de mudanças tecnológicas. Curitiba: Psicologia Dossiê, 2015.

TERRA, B. Inovação. Rio de Janeiro: Edição dos autores, 2019.

WEITEN, W. Introdução à psicologia. São Paulo: Cengage Learning, 2008. 